\title{
Solvent Effect on the Fluorescence Response of Hydroxycoumarin Bearing a Dipicolylamine Binding Site to Metal Ions
}

\author{
Hiroyuki Kobayashi, Kohei Katano, Takeshi HaShimoto, and Takashi HaYaShITA ${ }^{\dagger}$ \\ Department of Materials and Life Sciences, Faculty of Science and Technology, Sophia University, 7-1 Kioi-cho, \\ Chiyoda, Tokyo 102-8554, Japan
}

\begin{abstract}
The fluorescence behavior of a probe dpa-HC, which has a coumarin derivative that acts as a fluorophore and a dipicolylamine (DPA) unit that functions as a metal ion-recognition site, was investigated with various metal ions in aqueous and several non-aqueous solvents. In aqueous solution, the fluorescence of dpa-HC was enhanced by $\mathrm{Zn}^{2+}$ and $\mathrm{Cd}^{2+}$, but was quenched by other metal ions. On the other hand, in an acetonitrile solution, only $\mathrm{Mg}^{2+}$ enhanced the fluorescence, and the addition of a small amount of water quenched this fluorescence. This dramatic selectivity change is explained by stabilization of a metal-dpa-HC complex due to acetonitrile coordination and ON-OFF switching of the intramolecular photoinduced electron transfer (PET) from the nitrogen lone pair of DPA to the coumarin derivative.
\end{abstract}

Keywords Ion recognition, dipicolylamine, solvent effect, fluorescence response, chemosensor

(Received July 10, 2014; Accepted September 8, 2014; Published November 10, 2014)

\section{Introduction}

Metal ions, such as $\mathrm{Ca}^{2+}$ and $\mathrm{Mg}^{2+}$, exist in the living body where they play vital roles. For example, $\mathrm{Mg}^{2+}$ regulates hormone release, muscle contraction, and cell proliferation. Studies have indicated that $\mathrm{Mg}^{2+}$ is a crucial modulator of cell function, and the knockdown of genes coding for magnesium transporters leads to cell death., ${ }^{1,2}$

Fluorescent probes with high sensitivity and selectivity have become a powerful non-destructive tool for real-time monitoring. ${ }^{3,4}$ Fluorescent probes can sensitively detect toxic metal ions in the environment. Moreover, the emergence of metal ion imaging to examine changes in the intracellular distribution and the mobilization upon physiological or pathological stimuli is expected within the decade. ${ }^{1}$

In recent years, new fluorescence-based applications have been developed, and some probes have a dipicolylamine (DPA) unit as the ion-recognition site. Dipicolylamine has a tridentate ligand with three nitrogen donors to afford good selectivity for $\mathrm{Zn}^{2+}$ and $\mathrm{Cd}^{2+}$, and leaves the coordination sites free for anion binding. ${ }^{5}$ Many groups have reported that receptors having Zn(II)-DPA binding sites show high selectivity for phosphate oxoanions in aqueous solution, and because of this much attention has been given to $\mathrm{Zn}$ (II)-DPA anion receptors because such molecules are potentially useful tools for sensing biologically important anions. ${ }^{5,6}$ Fluorescent receptors for $\mathrm{Mg}^{2+}$, which have diaza-18-crown-6, $\beta$-diketone, and calixarene moieties for ion recognition, heve been reported. ${ }^{7-9}$ However, those receptors could not discriminate $\mathrm{Mg}^{2+}$ from $\mathrm{Ca}^{2+}$ due to the similar chemical properties of those two cations. ${ }^{10}$ Thus, the development of fluorescent probes with higher specificity and

† To whom correspondence should be addressed.

E-mail: ta-hayas@sophia.ac.jp selectivity is being pursued in earnest.

In this study, a fluorescent probe, dpa-HC (8-(2,2'-dipicolylaminomethyl)-7-hydroxycoumarin), for metal ion recognition was synthesized according to a reported procedure. ${ }^{11}$ The fluorescence of dpa-HC may be affected by a solvent change because dpa-HC is sensitive to the solvent polarity, ${ }^{12,13}$ although details of the solvent effect have not yet been clarified. Herein, we examined the role of solvents in the fluorescence change of dpa-HC and discovered a dramatic selectivity change of dpa$\mathbf{H C}$ from $\mathrm{Zn}^{2+}$ and $\mathrm{Cd}^{2+}$ in water to $\mathrm{Mg}^{2+}$ in acetonitrile.

\section{Experimental}

\section{Reagents and chemicals}

2,2'-Dipicolylamine and 7-hydroxycoumarin were purchased from Tokyo Chemical Industry Co., Ltd. Other chemicals were obtained as special-grade reagents from Wako Pure Chemical Industries, Ltd., and were used as received. Water was doubly distilled and deionized by a Milli-Q water system (Millipore) before use.

The probe dpa-HC was synthesized by the following procedure (Scheme 1). ${ }^{11}$ 2,2'-Dipicolylamine (0.625 g, $\left.3.14 \mathrm{mmol}\right)$<smiles>O=c1ccc2ccc(O)cc2o1</smiles>
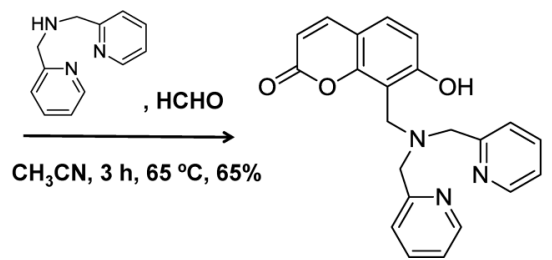

Scheme 1 Synthesis of 8-(2,2'-dipicolylaminomethyl)-7-hydroxycoumarin (dpa-HC). 


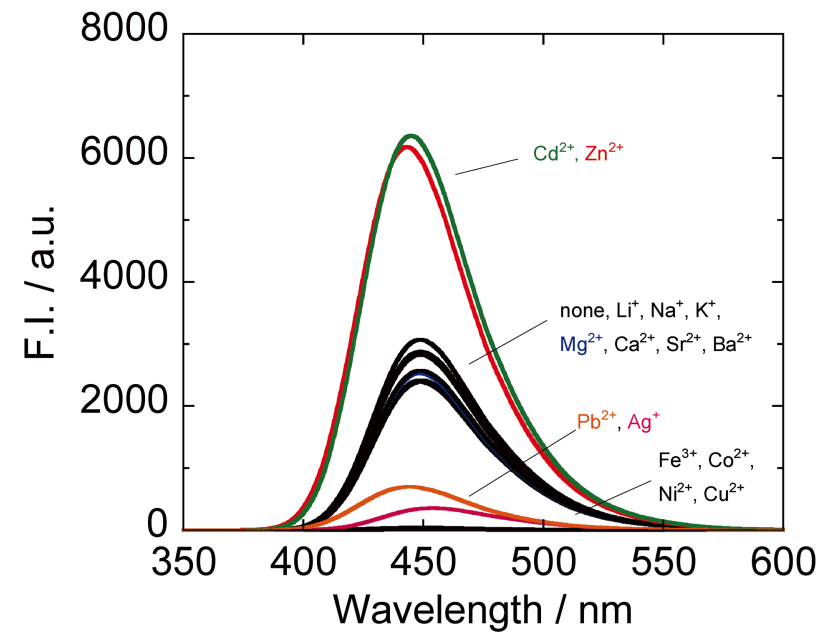

Fig. 1 Fluorescence spectra $\left(\lambda_{\mathrm{ex}}=340 \mathrm{~nm}\right)$ of dpa-HC $(50 \mu \mathrm{M})$ in the absence or presence of various metal ions ( 2 equiv. of $\mathrm{Li}^{+}, \mathrm{Na}^{+}, \mathrm{K}^{+}$, $\mathrm{Mg}^{2+}, \mathrm{Ca}^{2+}, \mathrm{Sr}^{2+}, \mathrm{Ba}^{2+}, \mathrm{Fe}^{3+}, \mathrm{Co}^{2+}, \mathrm{Ni}^{2+}, \mathrm{Cu}^{2+}, \mathrm{Zn}^{2+}, \mathrm{Ag}^{+}, \mathrm{Cd}^{2+}$, and $\left.\mathrm{Pb}^{2+}\right)$ in a HEPES buffer solution $(5 \mathrm{mM}, \mathrm{pH} 7.4$, acetonitrile/water $=1 / 99$, v/v) at $25^{\circ} \mathrm{C}$.

and formaldehyde ( $37 \%$ aqueous solution, $0.32 \mathrm{~mL}, 3.2 \mathrm{mmol}$ ) were dissolved in $30 \mathrm{~mL}$ of acetonitrile and the mixture was stirred at $60^{\circ} \mathrm{C}$ for $30 \mathrm{~min}$. To this was added 7-hydroxycoumarin $(0.501 \mathrm{~g}, 3.14 \mathrm{mmol})$, and the entire reaction mixture was heated at $65^{\circ} \mathrm{C}$ for $3 \mathrm{~h}$. The solvent was evaporated and chloroform was added. The organic layer was washed with deionized water to induce precipitate formation. The precipitate was filtered and washed well with deionized water. Purification by SEC (size exclusion chromatography) using chloroform afforded dpa-HC in $65 \%$ yield as a yellow solid $(0.76 \mathrm{~g}$, $2.04 \mathrm{mmol}) ;{ }^{1} \mathrm{H}$ NMR $\left(500 \mathrm{MHz}, \mathrm{CDCl}_{3}\right) \delta(\mathrm{ppm}) 8.51\left(\mathrm{~d}, J_{\mathrm{kj}}=\right.$ $4.5 \mathrm{~Hz}, 2 \mathrm{H}), 7.72\left(\mathrm{~d}, J_{\mathrm{ba}}=9.0 \mathrm{~Hz}, 1 \mathrm{H}\right), 7.68\left(\mathrm{td}, J_{\mathrm{ih}}, J_{\mathrm{ij}}=7.75\right.$, $1.5 \mathrm{~Hz}, 2 \mathrm{H}), 7.36\left(\mathrm{~d}, J_{\mathrm{cd}}=4.25 \mathrm{~Hz}, 1 \mathrm{H}\right), 7.33\left(\mathrm{~d}, J_{\mathrm{hi}}=8.0 \mathrm{~Hz}\right.$, $2 \mathrm{H}), 7.22\left(\mathrm{td}, J_{\mathrm{jk}}, J_{\mathrm{ji}}=6.13,1.0 \mathrm{~Hz}, 2 \mathrm{H}\right), 6.78\left(\mathrm{~d}, J_{\mathrm{dc}}=8.5 \mathrm{~Hz}\right.$, $1 \mathrm{H}), 6.11\left(\mathrm{~d}, J_{\mathrm{ab}}=9.25 \mathrm{~Hz}, 1 \mathrm{H}\right), 4.04(\mathrm{~s}, 2 \mathrm{H}), 3.89(\mathrm{~s}, 4 \mathrm{H})$; EI-HRMS $(m / z)$ calcd. for $\mathrm{C}_{22} \mathrm{H}_{19} \mathrm{~N}_{3} \mathrm{O}_{3}[\mathrm{M}]^{+} 373.1426$, found 373.1435; Anal. Calcd. for $\mathrm{C}_{22} \mathrm{H}_{19} \mathrm{~N}_{3} \mathrm{O}_{3}: \mathrm{C}, 70.76 ; \mathrm{H}, 5.13 ; \mathrm{N}$, 11.25. Found: C, 70.13; H, 5.08; N, 11.26.

\section{Apparatus}

${ }^{1} \mathrm{H}$ NMR spectra were measured with a JNM-EXC300 spectrometer (JEOL, Ltd.) or a JNM-ECA 500 spectrometer (JEOL, Ltd.). EI-MS spectra were recorded on a JMS-700 instrument (JEOL, Ltd.). Elemental analysis was performed with a Perkin Elmer PE2400 II apparatus. Fluorescence spectra were measured with a HITACHI F-7000 fluorescence spectrometer (Hitachi, Ltd.) equipped with a $1.0-\mathrm{cm}$ quartz cell. The scan speed was $60 \mathrm{~nm} \mathrm{~min}{ }^{-1}$. All fluorescence spectra were recorded under an aerated condition. UV-Vis spectra were measured with a HITACHI U-3900H UV-Vis spectrophotometer (Hitachi, Ltd.) equipped with a 1.0-cm quartz cell. The scan speed was $120 \mathrm{~nm} \mathrm{~min}{ }^{-1}$. X-ray diffraction data for the two compounds were analyzed on a Mercury CCD (Rigaku, Ltd.) equipped with a monochromator in the Mo $K_{\alpha}(\lambda=0.71069 \AA)$ incident beam. Each crystal was mounted on a glass fiber. The diffraction data were integrated and the structure was solved and refined using Crystal Structure Ver. 4.0.1. (Rigaku, Ltd.). All hydrogen atoms were placed in the calculated positions.

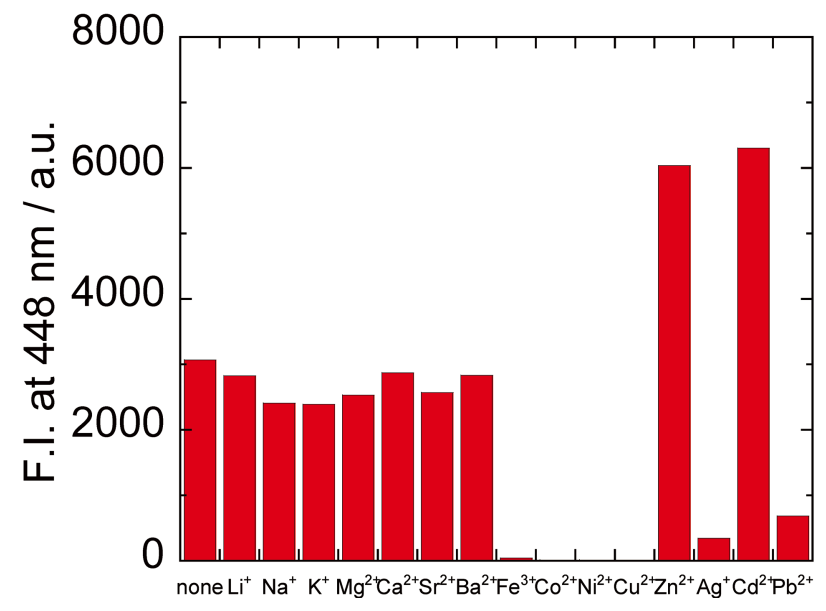

Fig. 2 Metal ion selectivity of dpa-HC $(50 \mu \mathrm{M})$ in a HEPES buffer solution $(5 \mathrm{mM}, \mathrm{pH} 7.4$, acetonitrile/water $=1 / 99, \mathrm{v} / \mathrm{v})$ at $25^{\circ} \mathrm{C}$. Bars represented the fluorescence intensity at $448 \mathrm{~nm}$ of dpa-HC $\left(\lambda_{\mathrm{ex}}=\right.$ $340 \mathrm{~nm})$ in the absence or presence of 2 equiv. of $\mathrm{Li}^{+}, \mathrm{Na}^{+}, \mathrm{K}^{+}, \mathrm{Mg}^{2+}$, $\mathrm{Ca}^{2+}, \mathrm{Sr}^{2+}, \mathrm{Ba}^{2+}, \mathrm{Fe}^{3+}, \mathrm{Co}^{2+}, \mathrm{Ni}^{2+}, \mathrm{Cu}^{2+}, \mathrm{Zn}^{2+}, \mathrm{Ag}^{+}, \mathrm{Cd}^{2+}$, and $\mathrm{Pb}^{2+}$

\section{Results and Discussion}

\section{Metal ion selectivity of dpa-HC in an aqueous solvent}

To examine the metal ion selectivity of $\mathbf{d p a}-\mathbf{H C}$ in an aqueous solution, we measured the fluorescence in the presence or absence of metal ions, including $\mathrm{Li}^{+}, \mathrm{Na}^{+}, \mathrm{K}^{+}, \mathrm{Mg}^{2+}, \mathrm{Ca}^{2+}, \mathrm{Sr}^{2+}$, $\mathrm{Ba}^{2+}, \mathrm{Fe}^{3+}, \mathrm{Co}^{2+}, \mathrm{Ni}^{2+}, \mathrm{Cu}^{2+}, \mathrm{Zn}^{2+}, \mathrm{Ag}^{+}, \mathrm{Cd}^{2+}$, and $\mathrm{Pb}^{2+}$. The fluorescence spectra were monitored in an aqueous solution containing $5.0 \times 10^{-5} \mathrm{M}\left(\mathrm{M}=\mathrm{mol} \mathrm{dm}^{-3}\right)$ dpa-HC, in the presence or absence of $1.0 \times 10^{-4} \mathrm{M}$ metal ions at $25^{\circ} \mathrm{C}$.

As shown in Figs. 1 and 2, the addition of 2 equiv. of alkali metal elements and group-2 element ions $\left(\mathrm{Li}^{+}, \mathrm{Na}^{+}, \mathrm{K}^{+}, \mathrm{Mg}^{2+}\right.$, $\mathrm{Ca}^{2+}, \mathrm{Sr}^{2+}, \mathrm{Ba}^{2+}$ ) exhibited no obvious effects on the fluorescence emission, whereas the addition of $\mathrm{Ni}^{2+}$ or $\mathrm{Cu}^{2+}$ decreased the fluorescence intensity. In contrast, the addition of $\mathrm{Zn}^{2+}$ and $\mathrm{Cd}^{2+}$ strongly enhanced the fluorescence intensity. The observed metal-ion selectivity of dpa-HC was almost the same as that previously reported by Yoon et al. ${ }^{11}$ and Kikuchi et al. ${ }^{14}$

The significant increase in fluorescence intensity could be explained as follows. The fluorescence response of dpa-HC is based on the photo-induced electron transfer (PET) mechanism. The inherent fluorescence of dpa-HC is quenched by the intramolecular PET from DPA to the coumarin derivative. However, upon addition of metal ions, the receptor chelates the metal ions to form stable complexes, thereby deactivating the quenching by PET due to stabilization of the receptor's HOMO so that it lies below the energy level of the fluorophore's HOMO, and increasing the fluorescence intensity of the coumarin moiety. ${ }^{15,16}$

Such transition metals as $\mathrm{Fe}^{2+}, \mathrm{Ni}^{2+}, \mathrm{Cr}^{2+}, \mathrm{Cu}^{2+}$, and $\mathrm{Co}^{2+}$ are paramagnetic ions with an unfilled $d$ shell, and are known to induce fluorescence quenching. Though $\mathrm{Fe}^{2+}$ and $\mathrm{Ni}^{2+}$ can take both high-spin and low-spin states, it is known that the fluorescence was quenched by the paramagnetic metal ions with a high-spin state.

The mechanisms for electron transfer (eT) and energy transfer (ET) are well defined, although various factors are known to cause fluorescence quenching. ${ }^{17}$ On the addition of $\mathrm{Cu}^{2+}$, the Cu-dpa-HC complex induced not chelation-enhanced fluorescence (CHEF), but fluorescence quenching by eT and ET 


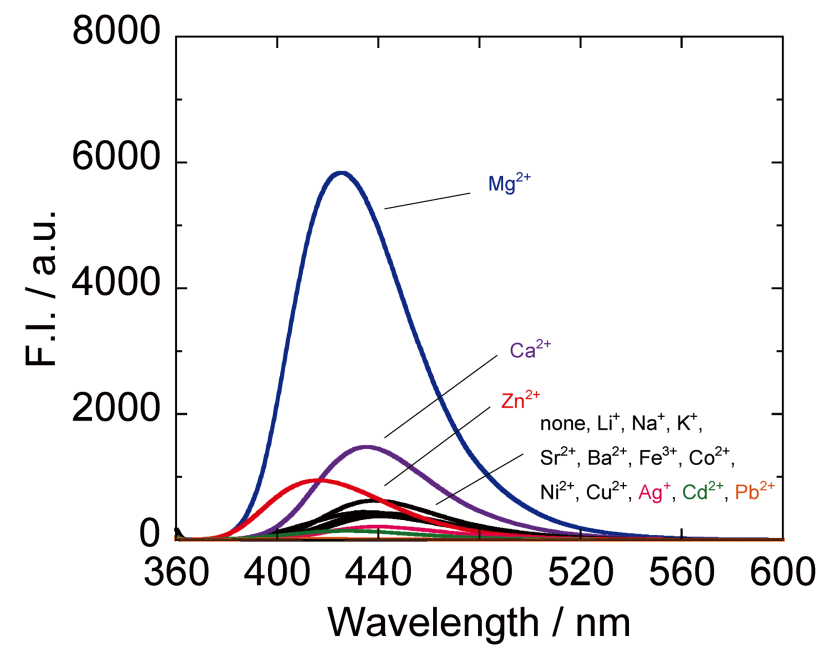

Fig. 3 Fluorescence spectra $\left(\lambda_{\mathrm{ex}}=356 \mathrm{~nm}\right)$ of dpa-HC $(50 \mu \mathrm{M})$ in the absence or presence of various metal ions ( 2 equiv. of $\mathrm{Li}^{+}, \mathrm{Na}^{+}, \mathrm{K}^{+}$, $\mathrm{Mg}^{2+}, \mathrm{Ca}^{2+}, \mathrm{Sr}^{2+}, \mathrm{Ba}^{2+}, \mathrm{Fe}^{3+}, \mathrm{Co}^{2+}, \mathrm{Ni}^{2+}, \mathrm{Cu}^{2+}, \mathrm{Zn}^{2+}, \mathrm{Ag}^{+}, \mathrm{Cd}^{2+}$, and $\left.\mathrm{Pb}^{2+}\right)$ in a acetonitrile solution (acetonitrile/water $=99 / 1, \mathrm{v} / \mathrm{v}$ ) at $25^{\circ} \mathrm{C}$.

to the metal ion. In the case of alkali and alkaline earth metal ions, the hydrated ions are much more stable than the metaldpa-HC (M-dpa-HC) complex; therefore, the formation of the M-dpa-HC complex does not proceed and the fluorescence of dpa-HC is quenched by intramolecular PET.

\section{Metal ion selectivity of $\mathbf{d p a}-\mathrm{HC}$ in organic solvent}

To clarify the metal ion selectivity of dpa-HC in an organic solvent, we observed the fluorescence responses in the presence or absence of metal ions. The fluorescence spectra in $99 \%$ acetonitrile- $1 \%$ water (v/v) containing $5.0 \times 10^{-5} \mathrm{M}$ dpa-HC were measured in the presence or absence of $1.0 \times 10^{-4} \mathrm{M}$ metal ions at $25^{\circ} \mathrm{C}$.

To our surprise, the addition of 2 equiv. of $\mathrm{Mg}^{2+}$ resulted in a significant enhancement of the fluorescence intensity in acetonitrile (Figs. 3 and 4), although $\mathrm{Mg}^{2+}$ exhibited no obvious effect on the fluorescence response of dpa-HC in water. The fluorescence intensities in the presence of $\mathrm{Zn}^{2+}$ and $\mathrm{Cd}^{2+}$ were markedly diminished when measurements were conducted in acetonitrile in comparison with those when measurements were done in water.

To examine the structures and binding conditions of M-dpaHC by changing the solvent, we measured the UV-Vis spectra of dpa-HC in the presence or absence of metal ions (Figs. S1 and S2, Supporting Information). In water, the UV-Vis spectra exhibited significant changes in the presence of $\mathrm{Zn}^{2+}$, whereas $\mathrm{Mg}^{2+}$ did not cause any spectral changes (Fig. S3, Supporting Information). In acetonitrile, on the other hand, dramatic changes were noted for $\mathrm{Mg}^{2+}$ (Fig. S4, Supporting Information). To obtain further evidence from the spectral changes, titrations experiments by the addition of $1-5$ equiv. of $\mathrm{Mg}^{2+}$ and $\mathrm{Zn}^{2+}$ in acetonitrile were performed, and significant 1:1 responses in the $\mathrm{UV}$-Vis spectra were observed for both $\mathrm{Zn}^{2+}$ and $\mathrm{Mg}^{2+}$ (Figs. S8 and S9, Supporting Information). No spectral changes were induced by the presence or absence of $\mathrm{Mg}^{2+}$, indicating that $\mathrm{Mg}^{2+}$ did not form the complex with dpa-HC in an aqueous solution. In general, $\mathrm{Mg}^{2+}$ is strongly hydrated, and it is difficult to form stable complex in water. However, dpa-HC can form $\mathrm{Mg}^{2+}$ complex in acetonitrile because acetonitrile promotes the coordination between $\mathrm{Mg}^{2+}$ and $\mathbf{d p a}-\mathbf{H C}$ by replacing the water

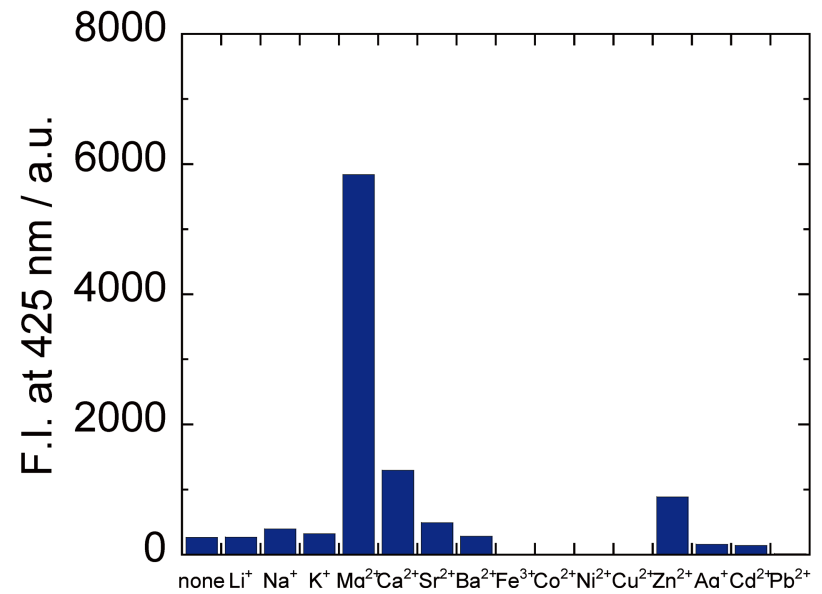

Fig. 4 Metal ion selectivity of dpa-HC $(50 \mu \mathrm{M})$ in acetonitrile solution (acetonitrile/water $=99 / 1, \mathrm{v} / \mathrm{v}$ ) at $25^{\circ} \mathrm{C}$. Bars represented the fluorescence intensity at $425 \mathrm{~nm}$ of dpa-HC $\left(\lambda_{\mathrm{ex}}=356 \mathrm{~nm}\right)$ in the absence or presence of 2 equiv. of $\mathrm{Li}^{+}, \mathrm{Na}^{+}, \mathrm{K}^{+}, \mathrm{Mg}^{2+}, \mathrm{Ca}^{2+}, \mathrm{Sr}^{2+}, \mathrm{Ba}^{2+}$, $\mathrm{Fe}^{3+}, \mathrm{Co}^{2+}, \mathrm{Ni}^{2+}, \mathrm{Cu}^{2+}, \mathrm{Zn}^{2+}, \mathrm{Ag}^{+}, \mathrm{Cd}^{2+}$, and $\mathrm{Pb}^{2+}$.

hydration with acetonitrile solvation. In contrast, the Zn-dpaHC complex was formed as confirmed by the marked red-shift of UV-Vis spectra, indicating that the hydroxyl group in the coumarin moiety was involved in the coordination of $\mathrm{Zn}^{2+}$ with dpa-HC. In an organic solvent, the absorption changes at $360 \mathrm{~nm}$ suggested that dpa-HC formed complexes with both $\mathrm{Zn}^{2+}$ and $\mathrm{Mg}^{2+}$ in a similar manner. For other metal ions, such as $\mathrm{Ag}^{+}$and $\mathrm{Pb}^{2+}$, no significant fluorescence and UV-Vis spectral response were noted in acetonitrile (Fig. 3 and Fig. S2 (Supporting Information)). ${ }^{18,19}$

The dpa-HC requires a suitable size for coordination with metal ions. This fact supports the similar complex formation ability of $\mathrm{Mg}^{2+}$ with $\mathrm{Zn}^{2+}$, since the ionic radii of $\mathrm{Zn}^{2+}$ and $\mathrm{Mg}^{2+}$ are nearly identical $\left(\mathrm{Zn}^{2+}\right.$ radius is $0.736 \AA$ whereas $\mathrm{Mg}^{2+}$ is $0.728 \AA^{20}$ ). X-ray structure analysis indicated that dpa-HC had difficulty in coordinating with a large metal ion because of conformational space limitations caused by the three nitrogen donors of DPA and the hydroxy group of the coumarin derivative (the single crystal structure ${ }^{21}$ is shown in Fig. S10, Supporting Information). Regarding the cation size, even though alkaline earth metal ions such as $\mathrm{Ca}^{2+}$ and $\mathrm{Ba}^{2+}$ have similar chemical properties to $\mathrm{Mg}^{2+}$, their radii are too large to allow for coordination with the recognition site. Those cations, therefore, exhibited no obvious effect on the fluorescence behavior affected by a solvent change. One reason why dpa-HC has high selectivity for $\mathrm{Mg}^{2+}$ may be the efficient interaction of the hydroxyl moiety (hard base) in dpa-HC with $\mathrm{Mg}^{2+}$ (hard acid), based on the Hard and Soft Acid and Bases (HSAB) theory. ${ }^{22}$

To determine the binding constant of dpa-HC, we assumed that dpa-HC formed a 1:1 complex with metal ions, and that the resultant fluorescence intensity changes as a function of the metal ion concentration were well fitted with the theoretical curve for 1:1 complex formation. The obtained binding constants $\left(K_{11}\right)$ are summarized in Table 1 . The fitting analysis is described in Supporting Information, section 4 (Figs. S11 S13, Supporting Information).

The results indicated that the binding constant of Mg-dpa-HC was higher in acetonitrile $\left(K_{11}=(1.01 \pm 0.92) \times 10^{7} \mathrm{M}^{-1}\right)$ than in water, whereas the binding constant of $\mathbf{Z n - d p a - H C ~ d e c r e a s e d ~}$ by changing the solvent from water $\left(K_{11}>10^{7} \mathrm{M}^{-1}\right)$ to acetonitrile $\left(K_{11}=(1.62 \pm 0.89) \times 10^{6} \mathrm{M}^{-1}\right)$. Thus, the binding 
affinity of the Zn-dpa-HC complex in acetonitrile was reduced, resulting in the low fluorescence intensity. This may be due to the coordination of acetonitrile to $\mathrm{Zn}^{2+}$, as mentioned later.

Fluorescence behavior by changing the acetonitrile/water ratio As described above, the metal ion selectivity of dpa-HC in aqueous and organic solvents showed different responses: dpa-HC displayed excellent selectivity for and sensitivity to $\mathrm{Zn}^{2+}$ and $\mathrm{Cd}^{2+}$ in an aqueous solvent, whereas it exhibited high selectivity for and sensitivity to $\mathrm{Mg}^{2+}$ in an organic solvent. To elucidate those interesting fluorescence responses, we examined the fluorescence behavior in both the absence or presence of metal ions by changing the water/acetonitrile composition.

As shown in Fig. 5, the fluorescence intensity of dpa-HC in the presence of $\mathrm{Mg}^{2+}$ was significantly enhanced in an acetonitrile/water mixed solvent containing $>95 \%$ acetonitrile. Mixed solvents containing lower percentages of acetonitrile exhibited no obvious effects on the fluorescence response. The results demonstrated that the fluorescence behavior of Mg-dpaHC changed noticeably in the presence of a small amount of water. Therefore, Mg-dpa-HC shows potential for use as a highly sensitive sensor for the quantitative measurement of a trace amount of water in organic solvents ${ }^{23}$ and real time imaging sensor for $\mathrm{Mg}^{2+}$ in the cell membrane.

Table 1 Binding constants of dpa-HC to metal ion $\left(K_{11}\right)$

\begin{tabular}{ccc}
\hline \multirow{2}{*}{$\begin{array}{c}\text { Metal } \\
\text { ion }\end{array}$} & \multicolumn{2}{c}{$K_{11} / \mathrm{dm}^{3} \mathrm{~mol}^{-1}$} \\
\cline { 2 - 3 } & $1 \%$ acetonitrile $-99 \%$ water & $99 \%$ acetonitrile $-1 \%$ water \\
\hline $\mathrm{Zn}^{2+}$ & $\mathrm{ND}\left(>10^{7}\right)$ & $(1.62 \pm 0.89) \times 10^{6}$ \\
$\mathrm{Cu}^{2+}$ & $(1.35 \pm 0.14) \times 10^{6}$ & $\mathrm{ND}\left(>10^{7}\right)$ \\
$\mathrm{Mg}^{2+}$ & - & $(1.01 \pm 0.92) \times 10^{7}$ \\
\hline
\end{tabular}

\section{${ }^{1} \mathrm{H}$ NMR studies}

To clarify the structure of the Mg-dpa-HC complex, ${ }^{1} \mathrm{H}$ NMR analyses were carried out in $100 \%$ acetonitrile- $d_{3}$ at $300 \mathrm{MHz}$. ${ }^{1} \mathrm{H}$ NMR signals appearing of around 7.0-8.5 ppm are attributed to the resonance corresponding to the DPA protons of dpa-HC. In contrast to the addition of $\mathrm{Mg}^{2+}$, the addition of 1 equiv. of $\mathrm{Ca}^{2+}$ and $\mathrm{Ba}^{2+}$ hardly changed the signals. To clarify the molecular motion in detail, titration analysis by the addition of $\mathrm{Mg}^{2+}$ was carried out. Figure 6 illustrates the result of a ${ }^{1} \mathrm{H}$ NMR titration analysis by the addition of $0-1.5$ equiv. of

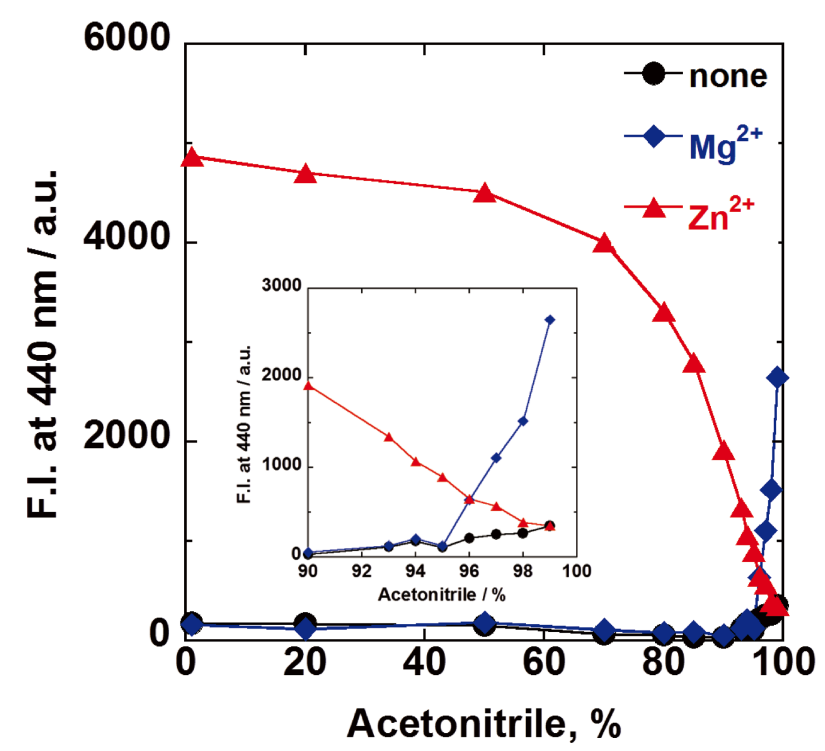

Fig. 5 Selectivity of dpa-HC $(50 \mu \mathrm{M})$ for metal ions (1 equiv. of $\mathrm{Mg}^{2+}, \mathrm{Zn}^{2+}$ ) in acetonitrile/water (volume ratio of acetonitrile: 1 to $99 \%)(\mathrm{v} / \mathrm{v})$ at $25^{\circ} \mathrm{C}\left(\lambda_{\mathrm{ex}}=367 \mathrm{~nm}\right)$.
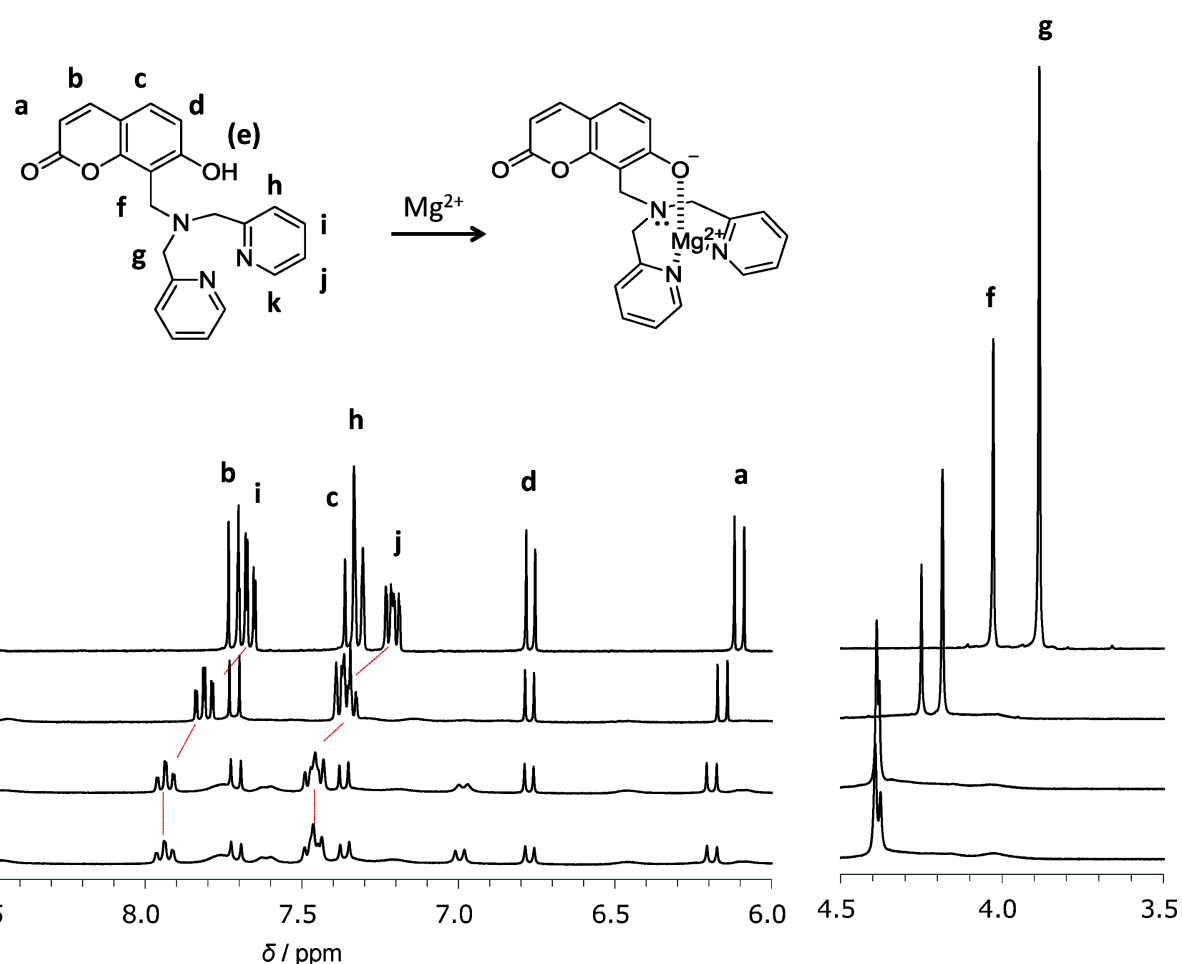

Fig. $6{ }^{1} \mathrm{H}$ NMR titration of dpa-HC in the presence of $0-1.5$ equiv. $\mathrm{Mg}^{2+}\left(300 \mathrm{MHz}, \mathrm{CD}_{3} \mathrm{CN}\right)$. 
$\mathrm{Mg}^{2+}$. Proton peaks of DPA located around 7.0-8.5 ppm showed downfield shifts, and new peaks appeared due to the formation of the $\mathrm{Mg}^{2+}$ complex. The spectra suggested that the molecular motion of the Mg-dpa-HC complex was restricted by the formation of a metal complex, which resulted in signal broadening.

\section{Fluorescence behavior induced by solvent changes}

To understand the solvent effects more clearly, fluorescence responses in water, DMSO, methanol, ethanol, and acetonitrile were examined.

As revealed in Fig. 7, dpa-HC only showed high selectivity for $\mathrm{Mg}^{2+}$ in acetonitrile. The results of UV-Vis spectra in water, DMSO, methanol, ethanol, and acetonitrile (Figs. S3 - S7, Supporting Information) indicated that the evidence of $\mathrm{Mg}^{2+}$ coordination with DPA moiety based on the changes in the UV-Vis spectra were only noted for the solvents of methanol, ethanol, and acetonitrile. Considering the fluorescence intensity difference before and after the addition of $\mathrm{Mg}^{2+}$, acetonitrile was superior to methanol and ethanol for obtaining the higher $\mathrm{Mg}^{2+}$ selectivity. The result also supported the finding that dpa-HC exhibited high selectivity for $\mathrm{Zn}^{2+}$ not in an organic solvent but in an aqueous solution.

From the decrease in the fluorescence intensity in noncoordinating solvents, it became clear that dpa-HC required coordinating solvents to exhibit high selectivity for $\mathrm{Mg}^{2+}$ Among the relative fluorescence intensities of free dpa-HC, dpa-HC in protic solvent such as methanol, ethanol and water showed the stronger fluorescence intensity, verifying that the protic solvent could enhance the fluorescence intensity of dpa-HC.
Fluorescence behaviors based on coordination ability

To clarify the structural effect of coordinating solvents, such as acetonitrile, benzonitrile and pyridine, the fluorescent behavior of M-dpa-HC was examined.

First, we compared acetonitrile with benzonitrile. The emission intensity of Mg-dpa-HC in acetonitrile was higher than that in benzonitrile (Fig. S14, Supporting Information).

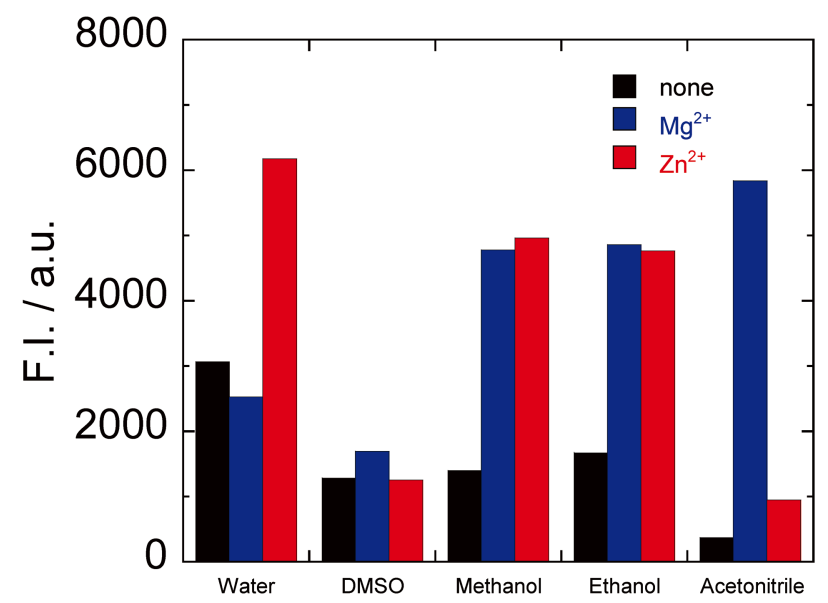

Fig. 7 Metal ion selectivity of dpa-HC $(50 \mu \mathrm{M})$ in different solvents (Water: $99 \%$ water-1\% acetonitrile (v/v), DMSO: $1 \%$ water-99\% DMSO (v/v), Methanol: 1\% water-99\% methanol (v/v), Ethanol: 1\% water-99\% ethanol (v/v), and Acetonitrile: $1 \%$ water-99\% acetonitrile $(\mathrm{v} / \mathrm{v}))$ at $25^{\circ} \mathrm{C}$. Bars represented fluorescence intensity of dpa-HC in the absence or presence of 2 equiv. of $\mathrm{Mg}^{2+}, \mathrm{Zn}^{2+}$.

\section{Aqueous solvent ( $1 \%$ acetonitrile - $99 \%$ water)}
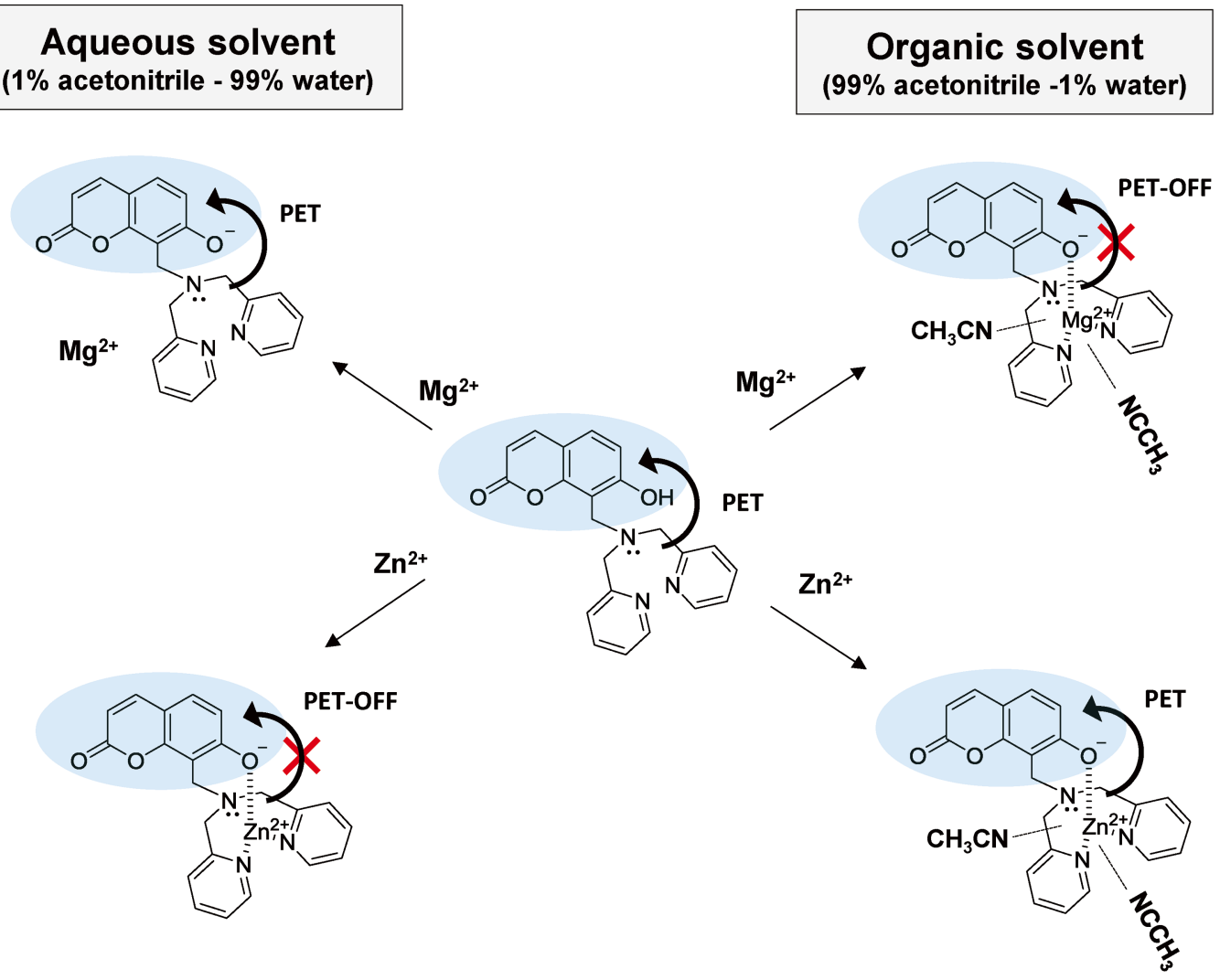

Scheme 2 Plausible mechanism of emission enhancement and quenching. 
This result indicated that benzonitrile had a low coordination ability to the metal ion in M-dpa-HC due to the electron withdrawing effect of benzene ring. Therefore, M-dpa-HC could be used as a sensor to recognize the structural differences of donor ligand derivatives in solution.

We then compared acetonitrile with pyridine based on their coordination ability. M-dpa-HC in acetonitrile showed an enhancement of the emission intensity upon the addition of pyridine, while the fluorescence response of dpa-HC exhibited no obvious effect for pyridine (Fig. S15, Supporting Information), indicating that the ligand exchange from acetonitrile to pyridine took place because the coordination ability of pyridine was higher than that of acetonitrile. This result supported that the solvent coordination affected the fluorescence behaviors of M-dpa-HC.

\section{Fluorescence emission mechanism}

Scheme 2 shows a plausible fluorescence emission mechanism. The inherent fluorescence of dpa-HC is quenched by the intramolecular PET from the nitrogen lone pair of DPA to the coumarin moiety. In the case of $\mathrm{Mg}^{2+}$, the coordinating solvents, such as acetonitrile, are required for complex formation with dpa-HC. The formation of a Mg-dpa-HC complex would deactivate the quenching by PET and increase the fluorescence intensity of the coumarin derivative.

Conversely, the type of solvent (water or acetonitrile) is irrelevant to the formation of the Zn-dpa-HC complex. It should be noted that the metal-DPA binding is markedly affected by the solvation network in acetonitrile. As a result, dpa-HC in acetonitrile does not form a stable complex with $\mathrm{Zn}^{2+}$ compared with dpa-HC in water. Thus, PET is not efficiently inhibited, even though the Zn-dpa-HC complex is formed, resulting in the low fluorescence intensity in acetonitrile.

\section{Conclusions}

We have synthesized a fluorescent probe $(\mathbf{d p a}-\mathbf{H C})$ for metal ion recognition, and evaluated its fluorescence response to various metal ions. The dpa-HC showed high selectivity for and sensitivity to $\mathrm{Zn}^{2+}$ and $\mathrm{Cd}^{2+}$ in water. On the other hand, the probe showed high selectivity for $\mathrm{Mg}^{2+}$ in acetonitrile. The inherent fluorescence of dpa-HC was quenched by the intramolecular PET from the nitrogen lone pair of DPA to the coumarin derivative. In the case of $\mathrm{Mg}^{2+}$, coordinating solvents, such as acetonitrile, were required for the complex formation of dpa-HC with $\mathrm{Mg}^{2+}$. The use of coordinating solvents could lead to the formation of a Mg-dpa-HC complex, thereby deactivating the quenching by PET and increasing the fluorescence intensity of the coumarin derivative. In the case of $\mathrm{Zn}^{2+}, \mathbf{Z n}$-dpa-HC complex was formed regardless of the solvent used (water or acetonitrile). However the metal-DPA binding was found to be strongly affected by the solvation network in acetonitrile. As a result, it was plausible that dpa-HC in acetonitrile did not form a stable complex with $\mathrm{Zn}^{2+}$ compared with dpa-HC in water. Thus, PET was not efficiently inhibited, resulting in a low fluorescence intensity, similar to the free dpa-HC. Consequently, we revealed a dramatic selectivity change of dpa-HC from $\mathrm{Zn}^{2+}$ and $\mathrm{Cd}^{2+}$ in water to $\mathrm{Mg}^{2+}$ in acetonitrile.

\section{Acknowledgements}

This work was supported by Grants-in-Aid for Scientific
Research from the Japan Society for the Promotion of Science (22350039 and 24655069).

\section{Supporting Information}

The ORTEP diagram of dpa-HC, UV-Vis spectra, theoritical formula, fluorescence spectra, and ${ }^{1} \mathrm{H}$ NMR spectra are enclosed in Supporting Information. These material are available free of charge on the Web at http://www.jsac.or.jp/analsci/.

\section{References}

1. V. Trapani, G. Farruggia, C. Marraccini, S. Iotti, A. Cittadini, and F. I. Wolf, Analyst, 2010, 135, 1855.

2. G. Farruggia, S. Iotti, L. Prodi, M. Montalti, N. Zaccheroni, P. B. Savage, V. Trapani, P. Sale, and F. I. Wolf, J. Am. Chem. Soc., 2006, 128, 344.

3. X. Chen, X. Tian, I. Shin, and J. Yoon, Chem. Soc. Rev., 2011, 40, 4783.

4. T. Guo, L. Cui, J. Shen, R. Wang, W. Zhu, Y. Xu, and X. Qian, Chem. Commun., 2013, 49, 1862.

5. H. T. Ngo, X. Liu, and K. A. Jolliffe, Chem. Soc. Rev., 2012, 41, 4928, and references therein.

6. Y. Kurishita, T. Kohira, A. Ojida, and I. Hamachi, J. Am. Chem. Soc., 2012, 134, 18779.

7. H. Komatsu, N. Iwasawa, D. Citterio, Y. Suzuki, T. Kubota, K. Tokuno, Y. Kitamura, K. Oka, and K. Suzuki, J. Am. Chem. Soc., 2004, 126, 16353.

8. K.-C. Song, M.-G. Choi, D.-H. Ryu, K.-N. Kim, and S.-K. Chang, Tetrahedron Lett., 2007, 48, 5397.

9. M. Ishida, Y. Naruta, and F. Tani, Angew. Chem., Int. Ed., 2010, 49, 91 .

10. Y. Ma, H. Liu, S. Liu, and R. Yang, Analyst, 2012, 137, 2313.

11. M.-J. Kim, K. M. K. Swamy, K.-M. Lee, A. R. Jagdale, Y. Kim, S.-J. Kim, K.-H. Yoo, and J. Yoon, Chem. Commun., 2009, 45, 7215.

12. Z.-Q. Hu, C.-S. Lin, X.-M. Wang, L. Ding, C.-L. Cui, S.-F. Liu, and H. Y. Lu, Chem. Commun., 2010, 46, 3765.

13 E. Hao, T. Meng, M. Zhang, W. Pang, Y. Zhou, and L. Jiao, J. Phys. Chem. A, 2011, 115, 8234.

14. S. Mizukami, S. Okada, S. Kimura, and K. Kikuchi, Inorg. Chem., 2009, 48, 7630.

15. A. P. de Silva, T. S. Moody, and G. D. Wright, Analyst, 2009, 134, 2385.

16. M. Kumai, S. Kozuka, M. Samizo, T. Hashimoto, I. Suzuki, and T. Hayashita, Anal. Sci., 2012, 28, 121.

17. J. S. Kim and D. T. Quang, Chem. Rev., 2007, 107, 3780.

18. J. Kwon, Y. J. Jang, Y. J. Lee, K. M. Kim, M. S. Seo, W. Nam, and J. Yoon, J. Am. Chem. Soc., 2005, 127, 10107.

19. J. Hatai and S. Bandyopadhyay, Chem. Commun., 2014, 50, 64.

20. R. D. Shannon, Acta Crystallogr., Sect. A, 1976, 32, 751.

21. CCDC 965963 contains supplementary crystallographic data and can be obtained free of charge from The Cambridge Crystallographic Data Centre via www.ccdc.cam.ac.uk/ data_request/cif.

22. R. G. Pearson, J. Chem. Educ., 1968, 45, 643.

23. Y. Ooyama, A. Matsugasako, K. Oka, T. Nagano, M. Sumomogi, K. Komaguchi, I. Imae, and Y. Harima, Chem. Commun., 2011, 47, 4448. 